\title{
The Need for a High-Accuracy, Open-Access Global DEM
}

\author{
Guy J-P. Schumann ${ }^{1,2,3 *}$ and Paul D. Bates ${ }^{1}$ \\ ${ }^{1}$ School of Geographical Sciences, University of Bristol, Bristol, United Kingdom, ${ }^{2}$ Remote Sensing Solutions Inc., Monrovia, \\ CA, United States, ${ }^{3}$ RSS-Hydro S.à.r.l.-S, Innovation Hub Dudelange, Dudelange, Luxembourg
}

Keywords: DEM (digital elevation model), hazard \& risk, accuracy, open access, global-local processing

\section{LIMITATIONS OF CURRENT OPEN-ACCESS DEMS}

Digital elevation models (DEM) are recognized as a core spatial dataset required for many environmental applications. However, the availability of comprehensive DEMs for water resources studies is rather limited and limitations of current, free or open-access DEMs are well-known. Freely available and global scale DEMs, such as that from the Shuttle Radar Topography Mission (SRTM) or from the Advanced Spaceborne Thermal Emission and Reflection Radiometer (ASTER) mission exhibit large vertical errors which are exacerbated over complex topography and they cannot resolve microtopographic variations in relatively flat terrain (Gallien et al., 2011; Chu and Lindenschmidt, 2017). For instance, SRTM mission requirements defined absolute and relative elevation errors of 16 and $6 \mathrm{~m}$, respectively (Rabus et al., 2003). Even though several studies have found actual errors to be considerably smaller than the requirements (see e.g. Schumann et al., 2008; Patel et al., 2016), the inherent errors in the SRTM-DEM are still notably unacceptable. Over the

OPEN ACCESS

Edited by:

Nils Moosdorf

Leibniz Centre for Tropical Marine

Research (LG), Germany

Reviewed by:

Norbert Pfeifer,

Vienna University of Technology,

Austria

${ }^{*}$ Correspondence:

Guy J-P. Schumann gjpschumann@gmail.com

Specialty section: This article was submitted to Hydrosphere,

a section of the journal

Frontiers in Earth Science

Received: 22 August 2018 Accepted: 23 November 2018 Published: 04 December 2018

Citation:

Schumann GJ-P and Bates PD (2018)

The Need for a High-Accuracy,

Open-Access Global DEM.

Front. Earth Sci. 6:225.

doi: 10.3389/feart.2018.00225 years, several processing algorithms and approaches for merging with other elevation datasets have been proposed to increase accuracy and remove vegetation biases (Baugh et al., 2013; Robinson et al., 2014; O'Loughlin et al., 2016; Yamazaki et al., 2017; Yue et al., 2017). However, whilst such derived versions are widely used, they still typically exhibit errors in the vertical much larger than those acceptable for many applications.

For instance, current global DEMs cannot resolve the detail of terrain features that control flooding (Schumann et al., 2014). Kenward et al. (2000) assessed the effects of different largescale DEMs on hydrologic runoff predictions and highlighted that different DEMs can lead to a difference of almost $10 \%$ in runoff predictions. Sanders (2007) examined the suitability of different online DEMs for flood modeling, including the US National Elevation Dataset (NED), Shuttle Radar Topography Mission (SRTM) data, airborne interferometric synthetic aperture radar (InSAR) data, and the Light Detection and Ranging (LIDAR) data. The study concluded that DEMs based on InSAR technology, including SRTM, suffer from radar noise and require prior processing while the NED DEM was remarkably smooth and may overestimate inundation extent. Nevertheless, Sanders (2007) highlighted the utility in SRTM as a global source of terrain data for flood modeling, as successfully demonstrated by e.g., Sampson et al. (2015). In a similar study, Li and Wong (2010) argued further that inundated areas from a flood simulation, albeit a simplistic case in their study, vary significantly across different DEM data sources. In another study dedicated to hydrologic applications, Mukherjee et al. (2013) evaluated the vertical accuracy of open source DEMs (ASTER and SRTM) and concluded that slope and drainage network delineation are largely violated compared to their reference DEM. As illustrated by Walker and Willgoose (1999), even higher accuracy published DEMs from aerial photogrammetry may be significantly different from ground truth, especially when looking at smaller catchments or applications for which localized errors in the elevation can have detrimental effects on local scale applications.

Another serious limitation of most freely available global DEMs, such as the SRTM-DEM acquired in February 2000, is that they are now very dated. Acquisition is not routinely repeated, 
whereas most national DEM programs acquiring photogrammetric or LiDAR DEMs, are repeated at regular multi-annual intervals. Consequently, any significant geomorphological change in topography as well as any man-made alteration of the Earth surface since the time of data acquisition will not be captured in global DEMs. Of course, this can have significant consequences when predicting for instance flood events in locations where previous events are known to have altered local topography considerably. More strikingly, there are now nearly 1.5 billion more people on earth compared to when SRTM was acquired, and every single one of them will have contributed to re-shaping the surface topography of our planet in some way. In this context, James et al. (2012) for instance noted that important geomorphological changes can occur over decadal timescales, and even more rapidly during extreme events and significant human alterations of landscapes (e.g., mining etc.).

It is clear that currently available global DEMs cannot be used to accurately simulate or predict local scale processes or impacts thereof. Even after considerable preprocessing to remove significant biases (due to vegetation and other physical structures) and to reduce inherent vertical errors, publicly available global DEMs still suffer from inaccuracies oftentimes orders of magnitude greater than length scales of the processes that are simulated. For instance, the residual vertical error in the SRTM DEM is for most river gradients orders of magnitude higher than the magnitude of the flood waves in those rivers (Bates et al., 2013). Consequently, it becomes very difficult to accurately model floods, and other inherently local phenomena, with current coarse resolution global DEMs, such as the SRTM-DEM. Local-scale skill is key, and this needs higher resolution and accuracy terrain data than currently available at large coverage. Furthermore, large scale hazard models are typically validated for rural areas, but all the major impacts are felt in urban zones where relevant process length scales are much higher; however, it is in urban areas where current global DEMs break down.

\section{REQUIREMENTS OF A GLOBAL HIGH-ACCURACY OPEN-ACCESS DEM}

\section{Level of Accuracy}

Spatial resolution, absolute error in the vertical, and accuracy in relative gradient (slope) are all important attributes of a DEM, and the requirements of those need to be properly established. Figure 1 puts available DEM technology in context of the requirements for spatial resolution and vertical accuracy for different scales of application.

Whilst views on the impact of spatial resolution may be more varied, depending on the complexity of the process simulated or indeed the DEM source (Horritt and Bates, 2001; Fewtrell et al., 2008; Li and Wong, 2010), absolute and relative accuracy in the vertical is crucial and even small vertical errors can have significant impacts on the application accuracy, especially at the local scale.
LeFavour and Alsdorf (2005) showed that for calculating a reliable slope from SRTM, reach lengths need to extend sufficient distances to accommodate the height errors. They developed the following simple relationship to determine the appropriate reach length (RL):

$$
2 \sigma / \mathrm{RL}=\mathrm{S}_{\min }
$$

For example, to be able to reproduce the minimum slope, $\mathrm{S}_{\mathrm{min}}$, along the very shallow gradient mainstem of the Amazon River of $1.5 \mathrm{~cm} / \mathrm{km}$ found by Birkett et al. (2002) using Topex/POSEIDON radar altimetry, the appropriate RL would need to be of $733 \mathrm{~km}$ in order to accommodate the $\pm 5.51 \mathrm{~m}$ height error that LeFavour and Alsdorf (2005) derived. In a similar study of the River Po in Northern Italy, Schumann et al. (2010) showed that when using an adequate RL, SRTM-DEM can be used to estimate river gradients almost as reliably as LiDAR data, albeit with much higher levels of uncertainty in the data.

Supposedly, Airbus Defense and Space's WorldDEM ${ }^{\mathrm{TM}}$ based on the TanDEM-X data, provides a global DEM of unprecedented quality, accuracy, and coverage with a vertical accuracy of $2 \mathrm{~m}$ (relative) and better than $6 \mathrm{~m}$ (absolute) at a $12 \mathrm{~m}$ spatial resolution (Riegler et al., 2015). While it is true that the accuracy may surpass that of any global satellite-based elevation model available, WorldDEM is not a free, open-access DEM and probably will therefore not define a new geospatial standard in global elevation models. Also, the errors stated, both in the absolute and relative are hardly sufficient for local-scale applications requiring an accuracy in the vertical of at least $0.5 \mathrm{~m}$ (Figure 1). Nonetheless, a number of recent studies have demonstrated that with expert processing, TanDEM-X data can be successfully employed to model flood hazard (Mason et al., 2015, 2016; Gutenson et al., 2017). It is worth noting that whilst this DEM may be more accurate than the SRTM-DEM, it is (also) not a bare-earth DEM and so deriving an accurate terrain model from the TanDEM-X source data would require significant time and resources.

Vricon (owned by Saab and DigitalGlobe) produces a very high resolution near-global digital surface and terrain model (DSM, DTM) at $0.5 \mathrm{~m}$ spacing using commercial multi-pair satellite imagery from DigitalGlobe, with a vertical absolute accuracy of $3 \mathrm{~m}$ and $1 \mathrm{~m}$ relative accuracy, according to the data provider (Vricon, 2018). They also generate a $10 \mathrm{~m} \mathrm{DSM}$ of the same accuracy specifications from the $0.5 \mathrm{~m}$ resolution DSM. Again, such a near-global DEM could be game-changing for many applications but is currently not available as an open-access product. As a highly successful open-access flagship example using this type of imagery and technology, the $\operatorname{ArcticDEM}^{1}$ is an NGA-NSF public-private initiative to automatically produce a high-resolution, high quality digital surface model (DSM) of the Arctic using optical stereo imagery, high-performance computing, and open source photogrammetry software.

\section{Different Data Acquisition Technology}

As illustrated in Figure 1, many different proven technologies exist to acquire DEMs, however, more importantly, there is

\footnotetext{
$\overline{{ }^{1} \text { https://www.pgc.umn.edu/data/arcticdem/ }}$
} 


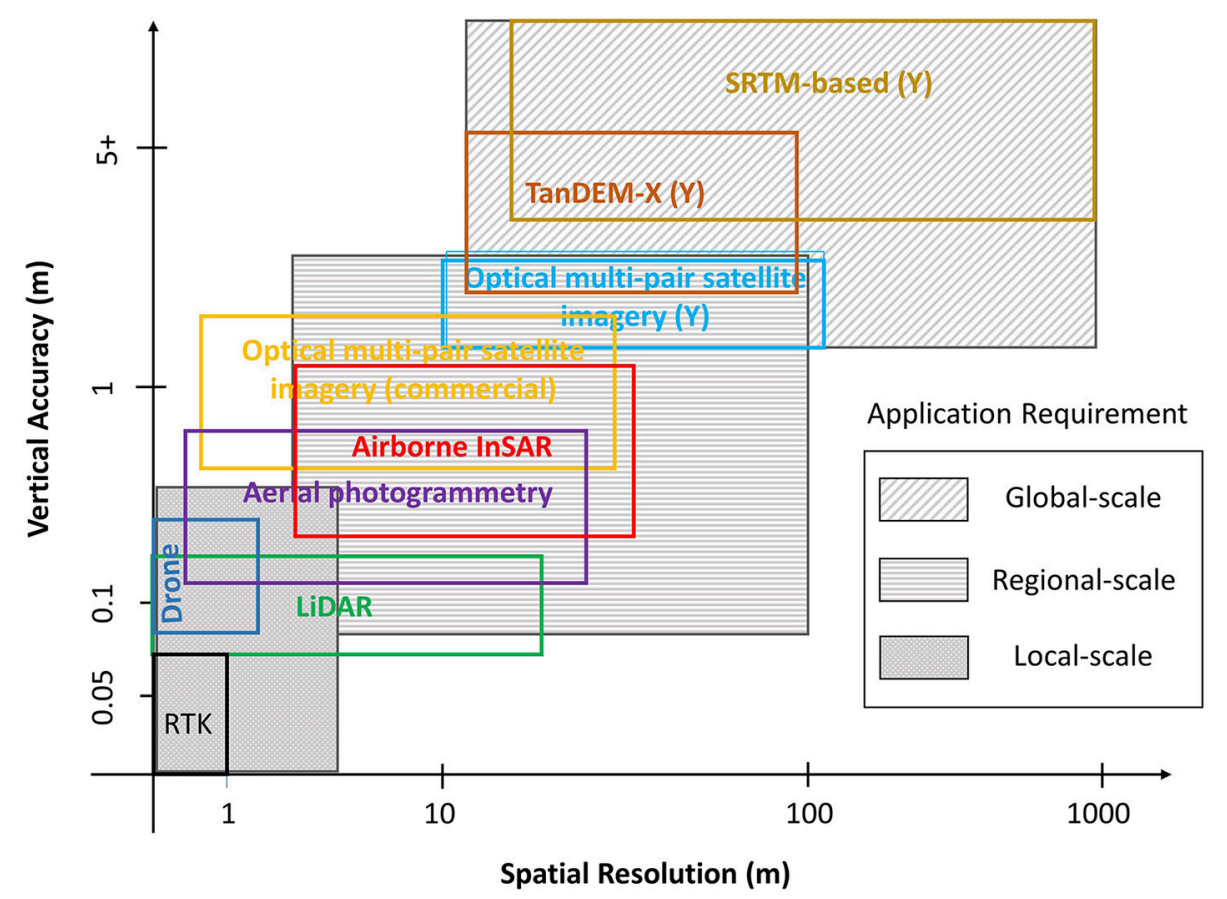

FIGURE 1 | Available DEM technology in context of requirements in spatial resolution and vertical accuracies for different scales in application. Note that $(Y)$ designates: "Yes" for global DEM available with at least a "for non-commercial use" license attached.

no need for a new technology in order to meet the accuracy requirements shown, even for local-scale applications. This has also been argued by Schumann et al. (2014) who suggested that an advanced global DEM would use existing LiDAR data and stereo satellite images, and new LiDAR elevation data could be acquired on board disaster-relief aircraft or on drones deployed over flood plains. The operation costs would therefore be substantially cheaper than most satellite missions. Schumann et al. (2016) further stated that such a DEM could be achieved from a consortium of industry, governments and humanitarian agencies and would undoubtedly be the environmental equivalent of the Human Genome Project (HGP; NIH, 2010) but at a fraction of the cost (see Sampson et al., 2016).

Hence, the innovation of creating a high-accuracy, open-access global DEM would merely lie in merging and quality controlling different "tiles" from different acquisition technologies and, prior to that, establishing the same metadata for those tiles, on a standardized (vertical) datum and map projection, such as for instance the recently proposed Discrete Global Grid System ${ }^{2}$ (DGGS). The goal of DGGS is to enable rapid assembly of spatial data without the difficulties of working with projected coordinate reference systems. DGGS would provide the capability to properly integrate global geospatial, social, and economic information. It also allows communities with data attributed to fundamentally different geographies to integrate this information in a single consistent framework. Also, new satellite sensor technology, such as on ICESat-2

${ }^{2}$ http://docs.opengeospatial.org/as/15-104r5/15-104r5.html (https://icesat-2.gsfc.nasa.gov), provides unprecedent elevation measurement accuracy which may be used to assist vertical datum matching and rectification (see Hall et al. (2012) for an example of this type of application with ICESat-1).

\section{Storage Facility}

At the White House Climate Data Initiative announcement in March $2014^{3}$, Google Inc. and many other industry entities, government agencies and NGOs, took significant steps in the right direction. Google Inc. committed one petabyte of cloud storage for climate data, as well as 50 million hours of highperformance computing and challenged the global innovation community to develop a high-accuracy global terrain model to help communities build resilience to anticipated climate impacts.

Although this private industry commitment is absolutely fantastic, it should be noted that privately-owned platforms and servers, even if made completely open with free registration, may not be accessible to all given that there may be access restrictions in place in some counties or at some governmental agencies. Therefore, it may be better to store a high-accuracy, open-access DEM on a fully accessible public server. Having said that, these are legalities that can eventually be sorted out easily, even with some flexibility from private sector industries.

\section{Licensing}

A high-accuracy, global DEM needs to be open-access and as such needs to be under a fully open license. Broadly speaking, an

\footnotetext{
${ }^{3}$ https://obamawhitehouse.archives.gov/blog/2014/03/19/climate-data-initiative-
} launches-strong-public-and-private-sector-commitments 
open license is one which grants permission to access, re-use and redistribute a work with no restrictions. Current low resolution and low accuracy global DEMs, such as the SRTM or ASTER are already distributed under a fully open license. Equally, many governments, in Europe, the U.S., Australia and elsewhere have already adopted an open license for national LiDAR elevation data, so extending this principle to a high-accuracy global DEM is easily achievable.

\section{WAY FORWARD}

Along the lines of the argument put forward by Schumann et al. (2014) to form a consortium of many different organizations working in a public-private partnership to create an open-access high-accuracy global DEM, McDougall et al. (2008) already suggested several years earlier that a collaborative approach has the potential to deliver improved outcomes with respect to the development of an open-access, high-quality DEM. A collaborative approach should optimize the existing investment across the public and private sectors and reduce potential duplication of effort.

It should be noted that we are not suggesting any highly laborious efforts, such as for instance, a country-by-country collection of already existing national scale high-resolution DEMs, but rather we suggest a consortium effort to look for a feasible solution using DEMs from already available

\section{REFERENCES}

Bates, P. D., Neal, J. C., Alsdorf, D., and Schumann, G. J. P. (2013). "Observing global surface water flood dynamics," in The Earth's Hydrological Cycle. Space Sciences Series of ISSI, eds L. Bengtsson, R.-M. Bonnet, M. Calisto, G. Destouni, R. Gurney, J. Johannessen, Y. Kerr, W. A. Lahoz, and M. Rast (Dordrecht: Springer), 839-852. doi: 10.1007/978-94-017-8789-5_16

Baugh, C. A., Bates, P. D., Schumann, G., and Trigg, M. A. (2013). SRTM vegetation removal and hydrodynamic modeling accuracy. Water Resour. Res. 49, 5276-5289. doi: 10.1002/wrcr.20412

Birkett, C. M., Mertes, L. A. K., Dunne, T., Costa, M. H., and Jasinski, M. J. (2002). Surface water dynamics in the Amazon Basin: application of satellite radar altimetry. J. Geophys. Res. 107:8059. doi: 10.1029/2001JD000609

Chu, T., and Lindenschmidt, K.-E. (2017). Comparison and validation of digital elevation models derived from InSAR for a flat inland delta in the high latitudes of Northern Canada. Can. J. Remote Sens. 43, 109-123. doi: 10.1080/07038992.2017.1286936

Fewtrell, T., Bates, P. D., Horritt, M., and Hunter, N. (2008). Evaluating the effect of scale in flood inundation modelling in urban environments. Hydrol. Process.22, 5107-5118. doi: 10.1002/hyp.7148

Gallien, T. W., Schubert, J. E., and Sanders, B. F. (2011). Predicting tidal flooding of urbanized embankments: a modeling framework and data requirements. Coastal Eng. 58, 567-577. doi: 10.1016/j.coastaleng.2011.01.011

Gutenson, J. L., Follum, M. L., Snow, A. D., and Wahl, M. D. (2017). Large-scale flood inundation modeling in data sparse environments using tandem-x terrain data. Open Water J. 4, 1-8. Available online at: https://scholarsarchive.byu.edu/ openwater/vol4/iss $2 / 4$

Hall, A. C., Schumann, G. J.-P., Bamber, J. L., Bates, P. D., and Trigg, M. A. (2012). Geodetic corrections to Amazon River water level gauges using ICESat altimetry. Water Resour. Res. 48:W06602. doi: 10.1029/2011WR010895

Horritt, M. S., and Bates, P. D. (2001). Effects of spatial resolution on a raster based model of flood flow. J. Hydrol. 253, 239-249. doi: 10.1016/S0022-1694(01)00490-5 commercial high-resolution technology, preferably merged with LiDAR (or other technology of similar capability) DEMs where already available as open data. The resulting DEM should be global and be made open-access, so that it can be more effectively utilized to support decision making on important issues such as water management and disaster assessment and mitigation. Negotiations among important players within the private industry, government agencies and international NGOs are already well underway [see for instance Schumann et al. (2014) and associated online comment $\left.{ }^{4}\right]$ but still there needs to be more substantial efforts to realize and speed-up progress in creating a high-accuracy, open-access DEM.

\section{AUTHOR CONTRIBUTIONS}

All authors listed have made a substantial, direct and intellectual contribution to the work, and approved it for publication.

\section{ACKNOWLEDGMENTS}

All opinions expressed in this article are the opinions of the authors and do not represent any government's or other entity's opinion.

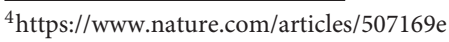

James, L. A., Hodgson, M. E., Ghoshal, S., and Latiolais, M. M. (2012). Geomorphic change detection using historic maps and DEM differencing: the temporal dimension of geospatial analysis. Geomorphology 137, 181-198. doi: 10.1016/j.geomorph.2010.10.039

Kenward, T., Lettenmaier, D. P., Wood, E. F., and Fielding, E. (2000). Effects of Digital Elevation Model Accuracy on Hydrologic Predictions. Remote Sens. Environ. 74, 432-444. doi: 10.1016/S0034-4257(00)00136-X

LeFavour, G., and Alsdorf, D. (2005). Water slope and discharge in the Amazon River estimated using the shuttle radar topography mission digital elevation model. Geophys. Res. Lett. 32:L17404. doi: 10.1029/2005GL023836

Li, J., and Wong, D. W. S. (2010). Effects of DEM sources on hydrologic applications. Comput. Environ. Urban Syst. 34, 251-261. doi: 10.1016/j.compenvurbsys.2009.11.002

Mason, D., Javier, G. P., Hannah, C., and Sarah, D. (2015). The potential of flood forecasting using a variable-resolution global digital terrain model and flood extents from synthetic aperture radar images. Front. Earth Sci. 3:43. doi: 10.3389/feart.2015.00043

Mason, D. C., Trigg, M., Garcia-Pintado, J., Cloke, H. L., Neal, J. C., and Bates, P. D. (2016). Improving the TanDEM-X digital elevation model for flood modelling using flood extents from synthetic aperture radar images. Remote Sens. Environ.173, 15-28. doi: 10.1016/j.rse.2015.11.018

McDougall, K., Liu, X., Basnet, B., and Apan, A. (2008). "Digital elevation model accuracy requirements for catchment management," in Queensland Spatial Conference 2008 (Surfers Paradise, QLD).

Mukherjee, S., Joshi, P. K., Mukherjee, S., Ghosh, A., Garg, R. D., and Mukhopadhyay, A. (2013). Evaluation of vertical accuracy of open source digital elevation model (DEM). Int. J. Appl. Earth Obs. Geoinf. 21, 205-217. doi: 10.1016/j.jag.2012.09.004

NIH (2010). Human Genome Project. Fact Sheet, National Institutes of Health. Available online at: https://report.nih.gov/nihfactsheets/ViewFactSheet.aspx? csid $=45$

O'Loughlin, F. E., Paiva, R. C., Durand, M., Alsdorf, D., and Bates, P. (2016). A multi-sensor approach towards a global vegetation corrected SRTM 
DEM product. Remote Sens. Environ. 182, 49-59. doi: 10.1016/j.rse.2016. 04.018

Patel, A., Katiyar, S. K., and Prasad,. V. (2016). Performances evaluation of different open source DEM using differential global positioning system (DGPS). Egypt. J. Remote Sens. Space Sci. 19, 7-16. doi: 10.1016/j.ejrs.2015.12.004

Rabus, B., Eineder, M., Roth, A., and Bamler, R. (2003). The shuttle radar topography mission-a new class of digital elevation models acquired by spaceborne radar. ISPRS J. Photogramm. Remote Sens. 57, 241-262. doi: 10.1016/S0924-2716(02)00124-7

Riegler, G., Hennig, S. D., and Weber, M. (2015). WorldDEM - A Novel Global Foundation Layer. Munich: The International Archives of the Photogrammetry, Remote Sensing and Spatial Information Sciences.

Robinson, N., Regetz, J., and Guralnick, R. P. (2014). EarthEnv-DEM90: a nearlyglobal, void-free, multi-scale smoothed, $90 \mathrm{~m}$ digital elevation model from fused ASTER and SRTM data ISPRS J. Photogramm. Remote Sens. 87, 57-67. doi: 10.1016/j.isprsjprs.2013.11.002

Sampson, C. C., Smith, A. M., Bates, P. D., Neal, J. C., Alfieri, L., and Freer, J. E. (2015). A high-resolution global flood hazard model. Water Resour. Res. 51, 7358-7381. doi: 10.1002/2015WR016954

Sampson, C. C., Smith, A. M., Bates, P. D., Neal, J. C., and Trigg, M. A. (2016). Perspectives on open access high resolution digital elevation models to produce global flood hazard layers. Front. Earth Sci. 3:85. doi: 10.3389/feart.2015. 00085

Sanders, B. F. (2007). Evaluation of on-line DEMs for flood inundation modeling. Adv. Water Resour. 30, 1831-1843. doi: 10.1016/j.advwatres.2007.02.005

Schumann, G., Di Baldassarre, G., Alsdorf, D., and Bates, P. D. (2010). Near realtime flood wave approximation on large rivers from space: application to the River Po, Italy. Water Resour. Res. 46. doi: 10.1029/2008WR007672

Schumann, G. J., Bates, P. D., Neal, J. C., and Andreadis, K. M. (2014). Fight floods on a global scale. Nature 507:169. doi: 10.1038/507169e
Schumann, G. J. P., Moller, D. K., and Mentgen, F. (2016). High-accuracy elevation data at large scales from airborne single-pass SAR interferometry. Front. Earth Sci. 3:88. doi: 10.3389/feart.2015.00088

Schumann, G. P. Matgen, P. Cutler, M. E. J. Black, A., Hoffmann, L., and Pfister, L. (2008). Comparison of remotely sensed water stages from LiDAR, topographic contours and SRTM, ISPRS. J. Photogram. Remote Sens. 63, 283-296. doi: 10.1016/j.isprsjprs.2007.09.004

Vricon (2018). The Globe in 3D. Available online at: https://www.vricon.com/ products/vricon-data-suite/ (Accessed August 17, 2018).

Walker, J. P., and Willgoose, G. R. (1999). On the effect of digital elevation model accuracy on hydrology and geomorphology. Water Resour. Res. 35, 2259-2268. doi: 10.1029/1999WR900034

Yamazaki, D., Ikeshima, D., Tawatari, R., Yamaguchi, T., O’Loughlin, F., Neal, J., et al. (2017). A high-accuracy map of global terrain elevations. Geophys. Res. Lett. 44, 5844-5853. doi: 10.1002/2017GL072874

Yue, L., Shen, H., Zhang, L., Zheng, X., Zhang, F., and Yuan, Q. (2017). Highquality seamless DEM generation blending SRTM-1, ASTER GDEM v2 and ICESat/GLAS observations. ISPRS J. Photogramm. Remote Sens. 123, 20-34. doi: 10.1016/j.isprsjprs.2016.11.002

Conflict of Interest Statement: The authors declare that the research was conducted in the absence of any commercial or financial relationships that could be construed as a potential conflict of interest.

Copyright (c) 2018 Schumann and Bates. This is an open-access article distributed under the terms of the Creative Commons Attribution License (CC BY). The use, distribution or reproduction in other forums is permitted, provided the original author(s) and the copyright owner(s) are credited and that the original publication in this journal is cited, in accordance with accepted academic practice. No use, distribution or reproduction is permitted which does not comply with these terms. 